\title{
The deep subsurface biosphere in igneous ocean crust: frontier habitats for microbiological exploration
}

\author{
Katrina J. Edwards ${ }^{1}{ }^{*}$, Andrew T. Fisher ${ }^{2}$ and C. Geoffrey Wheat ${ }^{3}$ \\ 1 Department of Biological Sciences, University of Southern California, Los Angeles, CA, USA \\ ${ }^{2}$ Department of Earth and Planetary Sciences, University of California Santa Cruz, Santa Cruz, CA, USA \\ ${ }^{3}$ Global Undersea Research Unit, University of Alaska Fairbanks, Fairbanks, CA, USA
}

Edited by:

Andreas Teske, University of North

Carolina at Chapel Hill, USA

\section{Reviewed by:}

John Stolz, Duquesne University, USA

Jens Kallmeyer, University of

Potsdam, Germany

${ }^{*}$ Correspondence:

Katrina J. Edwards, Department of

Biological Sciences, Division of

Marine Environmental Biology, 3616

Trousdale Blvd 91030, AHF 203, LoS

Angeles, CA, USA.

e-mail: kje@usc.edu
We discuss ridge flank environments in the ocean crust as habitats for subseafloor microbial life. Oceanic ridge flanks, areas far from the magmatic and tectonic influence of seafloor spreading, comprise one of the largest and least explored microbial habitats on the planet. We describe the nature of selected ridge flank crustal environments, and present a framework for delineating a continuum of conditions and processes that are likely to be important for defining subseafloor microbial "provinces." The basis for this framework is three governing conditions that help to determine the nature of subseafloor biomes: crustal age, extent of fluid flow, and thermal state. We present a brief overview of subseafloor conditions, within the context of these three characteristics, for five field sites where microbial studies have been done, are underway, or have been proposed. Technical challenges remain and likely will limit progress in studies of microbial ridge flank ecosystems, which is why it is vital to select and design future studies so as to leverage as much general understanding as possible from work focused at a small number of sites. A characterization framework such that as presented in this paper, perhaps including alternative or additional physical or chemical characteristics, is essential for achieving the greatest benefit from multidisciplinary microbial investigations of oceanic ridge flanks.

Keywords: microbiology, deep subsurface, ocean crust, basalt, ecology, provinces, marine

\section{INTRODUCTION}

Of all the potentially habitable deep subsurface environments on Earth, the igneous ocean crust is one most intriguing, being spatially extensive, voluminous, and (in many places) hospitable for development and maintenance of life. Yet, igneous crust remains among the least studied and most poorly understood of Earth's major biological habitats (Shrenk et al., 2009). Most studies on subseafloor crustal microbiology have focused on mid-ocean ridge (MOR) seafloor spreading areas. In contrast, much of the remaining $300,000 \mathrm{~km}^{3}\left(\sim 2.3 \times 10^{18} \mathrm{~m}^{3}\right.$ of pore fluid volume; Orcutt et al., 2011b) of potentially habitable igneous ocean crust is virtually unexplored for microbiology. This deep subseafloor biosphere, developed and maintained as part of ridge flank hydrothermal (RFH) systems, represents a relatively unexplored frontier for scientific discovery.

Researchers are pursuing fundamental questions concerning ridge flank crustal microbiology, including: what is the activity of life within ridge flanks? How are evolutionary forces expressed in these settings? What are the physical and chemical limits for survival and reproduction in the subseafloor? What is the biogeography of life in the subsurface and what are the most important dispersal mechanisms? What are the influences of subseafloor microbiology on global biogeochemical processes?

Ocean crust has existed through much of Earth's history, long before there were continents, and has been exposed to a range of chemical and thermal conditions that overlap with those found today. Therefore, the ocean crust is one of the oldest biomes on the planet; understanding how life developed to occupy and survive in this biome will help to answer fundamental questions about evolution and persistence of microbial communities on Earth. The ocean crust is large, and the flow of water, heat, and solutes between the crust and ocean rivals those from riverine sources (Mackenzie, 1992; Stein and Stein, 1994; Elderfield and Schultz, 1996; Wheat et al., 2003).

Elucidating the nature and function of ocean crustal microbial ecosystems is critical to understanding the global-scale storage and transfer of carbon, nutrients, and life-supporting metals over geological time. This understanding has implications for the early Earth, modern Earth, and perhaps other planetary bodies where there are mixing and reactions between rock, water, carbon, and heat (e.g., Cody et al., 2000; Chyba and Phillips, 2002).

Most geobiological research is conducted on continents, where environments and samples are readily accessible in the surface world. In the oceans, most studies occur in the water column, shallow sediments along continental margins, and near the surface of seafloor spreading centers. These are some of the easiest marine sites to locate and sample, although in general marine sites are more challenging to access than are sites on land. There are comparatively few studies of mineral-microbe interactions in $\mathrm{RFH}$ areas, even though hydrothermal systems in these areas represent an enormous fraction of the subseafloor microbial realm where mineral-microbe interactions are likely to play a critical role in biogeochemical processes and ecosystem function. Our understanding of the Earth as a geobiological system suffers if one 
of the most voluminous parts of this biome remains so under sampled.

There is an opportunity to accelerate the pace of microbial exploration, discovery, and experimentation in the ocean crust, in association with scientific ocean drilling. The initial science plan for the Integrated Ocean Drilling Program (IODP; 20032013; IODP, 2003), includes a major emphasis on the microbial biosphere and related studies of crustal formation, marine hydrogeology, biogeochemistry, and rock alteration. Ocean drilling has been profoundly important in developing new technology, linking multidisciplinary research projects, and providing access to samples and data that cannot be recovered in any other way. The science plan for the successor to IODP, the International Ocean Discovery Program (2013-2023; IODP, 2011), also includes a prominent focus on subseafloor microbiology. Yet fielding a major drilling effort involves considerable planning, engineering development, and funding, a lengthy process often requiring 5 years or more. Without rapid action, few new expeditions focusing on subseafloor microbiology will be completed during the next phase of scientific ocean drilling.

Advances and research in the subsurface biome are not limited by scientific drilling operations; much can also be learned from sampling materials with submersibles and remotely operated vehicles (ROVs) at sites where crustal fluids seep from the seafloor. Nevertheless, it is highly unlikely that researchers will develop enough ridge flank drilling and submersible studies to provide a statistically robust global data set from RFH systems; the extent of ridge flank biomes is simply too vast, and the complexity and cost of fielding dozens of field programs is too great. Instead, strategies are needed to plan for ridge flank studies of subseafloor microbiology and related disciplines by identifying critical parameters and processes that occur across a wide range of natural conditions. Many of the key parameters are understood based on theoretical considerations, laboratory studies, and (limited) in situ work completed to date. The delineation of microbiological "provinces" in the igneous ocean crust, based on consideration of "geologically and geographically coherent regions of the subseafloor that may serve as potential microbial habitats" (Schrenk et al., 2009), provides an important framework for identifying targets and planning for efficient and successful sampling.

In the present study, we apply this process- and province-based approach to identifying conditions that define the scientifically compelling potential habitats in oceanic ridge flanks. Based on delineation of key parameters, one can select a modest number of field areas where rapid progress can be achieved. Sites and systems selected on the basis of their locations within a parameter space of ridge flank processes can subsequently be used to develop (and eventually test) fully coupled models of deep subsurface microbial life. Initial field studies can also help to determine where gaps in understanding may persist, and help with identification of essential needs for field surveys, tools, and experiments.

In the next section of this paper, we explore some of the key physical and chemical parameters that should have a significant influence on the development and maintenance of subseafloor microbiological systems, focusing on those parameters that are most readily measured on the basis of regional surveys. We use a subset of these parameters to delineate a range of physical and chemical conditions, and describe selected field sites that occupy relatively narrow ranges of these parameters. We also identify where there are remaining gaps in this representation of ridge flank microbial provinces. The present study focuses on volcanichosted ("hard rock") biomes within deep-sea ridge flanks, but similar approaches are readily developed for other settings (deepsea sedimentary environments, very young seafloor near spreading centers, continental shelves, etc.) and sets of parameters (productivity in the overlying water, water depth, proximity to continents, etc.).

\section{THERMAL, GEOCHEMICAL, HYDROLOGICAL, AND GEOLOGICAL REGIMES}

Most new oceanic crust forms where tectonic plates separate at divergent boundaries, resulting in partial melting of ultramafic mantle rocks to form basaltic magma. This process occurs under a wide range of spreading rates and tectonic regimes, yet results (to a first order) in a remarkably consistent ocean crustal stratigraphy, as originally defined from study of ophiolites (Raitt, 1963; Moores and Vine, 1971; Shor et al., 1971; Cann, 1974). Extrusive volcanic rocks having a basaltic composition generally form the upper $500-1000 \mathrm{~m}$ of ocean crust, and are underlain by $5-6 \mathrm{~km}$ of intrusive mafic rocks (basalt, gabbro). There are common variations in this typical crustal structure, particularly where plates spread at slow rates $(\leq 3 \mathrm{~cm} /$ year $)$. At very low spreading rates, plate divergence is diffuse, and the seafloor lacks a readily identifiable spreading center. In these and in other areas, the ocean crust is frequently faulted and delaminated almost as quickly as it is formed, exposing deeper crustal levels at the seafloor. This has important biogeochemical implications for associated microbial ecosystems. Additional deviations in crustal structure occur at fracture zones and around seamounts, where additional tectonic and volcanic processes are active.

The nature of processes and conditions at depth below seafloor spreading centers remain poorly known and is a subject of debate within the scientific community. For example, geophysical and geochemical studies from some sites have been interpreted to indicate that relatively cool conditions may extend completely through the crust close to seafloor spreading centers, with rapid circulation of cool seawater into the upper mantle, extracting a large fraction of crustal heat (e.g., Dunn et al., 2000; VanTongeren et al., 2008; Spinelli and Harris, 2011). In contrast, comprehensive water column plume studies along spreading centers suggest that the advective heat output from hydrothermal circulation can account for the cooling of only the upper 1-2 km of the crust (Baker, 2007), and crustal alteration studies on some settings reveal a lack of evidence for the penetration of cool fluids into gabbros of the lower crust (e.g., Dunn et al., 2000; Humphris and Cann, 2000; Coogan et al., 2007). Secondary fluid circulation near spreading centers, penetrating only a short distance below the seafloor, could result in sustained cool conditions in the upper crust, even where and when heat extraction by deeply circulating fluids is incomplete. In aggregate, there is compelling evidence from many sources that at least the upper $1-2 \mathrm{~km}$ of ocean crust is cooled efficiently by circulating fluids at and near many seafloor spreading centers, and cool temperatures may predominate in the crust in these regions, 
except in the immediately vicinity of recently emplaced magma or at high-temperature hydrothermal upflow zones.

The thermal state of the upper crust as it moves away from seafloor spreading centers is highly variable, depending on factors such as the nature and rate of sedimentation, extent and frequency of faulting, and the occurrence of off axis volcanism. The latter is often not widely appreciated, but recent studies suggest that the seafloor is dotted with $10^{6}-10^{7}$ seamounts having an elevation of $100 \mathrm{~m}$ or more above the surrounding basaltic crust (Hillier and Watts, 2007; Wessel et al., 2010). These features facilitate hydrogeologic exchange between the crust and ocean for millions of years (Fisher and Wheat, 2010).

Standard lithospheric (conductive) cooling models generally suggest that crustal heat output decreases as $1 / \sqrt{ }$ age (e.g., Parsons and Sclater, 1977), but in practice conditions differ considerably between sites having similar ages. On a global basis, the throughput of RFH fluid is similar to the discharge of the global river system into the ocean; thus a volume equivalent to that of the global ocean is passed through the crust about once every $10^{5}-10^{6}$ years (e.g., Mottl and Wheat, 1994; Johnson and Pruis, 2003; Wheat et al., 2003). This is a very short residence time for the ocean in the crust when considered over the duration of Earth history. In addition, based on consideration of the volume of pore space available in the volcanic ocean crust, and the global rate of fluid throughput, the global residence time of fluids in the crust is relatively short, only $10^{3}-10^{4}$ years, about the same as the residence time of deep water in the northern Pacific Ocean.

High-temperature hydrothermal sites at seafloor spreading centers and other areas of active volcanism provide some of the most dramatic visual, chemical, thermal, and biologic expressions of fluid flow from the volcanic ocean crust. High-temperature vent fluids differ in composition from seawater in numerous important ways. These fluids tend to be depleted in magnesium and sulfate, rich in dissolved metals and calcium, and contain reduced forms of nitrogen, carbon, sulfur, and hydrogen. During circulation, high-temperature fluids may reach temperatures in excess of $350-400^{\circ} \mathrm{C}$, sterilizing the entrained seawater. However, when this fluid mixes with cool oxygenated bottom seawater, microbial growth can be rampant, for example producing "snow blower" events, where large amounts of flocculent biofilm materials are flushed from the seafloor (Haymond et al., 1993).

Another source for reduced chemical species in crustal fluids is sediment that overlies the volcanic crust. Microbial processes in sediment commonly lead to reducing pore fluids, which exchange diffusively with the underlying volcanic crustal reservoir (Elderfield et al., 1999; Wheat et al., 2000). Diffusive fluxes from the sediment can be the dominant control for the composition of some dissolved species in crustal fluids, resulting in a distinctly altered seawater composition.

However, in many cases the composition of fluids in many RFH systems may be only subtly different from that of bottom seawater. Within low temperature RFH systems, which are kept cool by the vigor of fluid exchange between the crust and ocean, crustal fluids will remain cool and oxic if the advective flux through the crust exceeds the aggregate of downward diffusive fluxes from overlying sediment and reaction with basement volcanic rocks. Relatively low temperatures in such systems minimize the amount and type of reduced nitrogen, carbon, sulfur, and hydrogen available in fluids for microbes within the basaltic crust, and tend to slow inorganic exchange. On average, the residence time of fluids within the crust on ridge flanks is orders of magnitude longer than that of MOR crustal fluids (Kadko and Moore, 1988; Fisher, 2003). In some cases, this can permit significant changes in the composition of ridge flank crustal fluids, even where reactions are kinetically slow.

Cool RFH systems have a profound influence on heat loss from the crust. And despite having a composition that is subtly different from bottom seawater, such systems can have a significant impact on the composition of the crust and seawater because the flows are so large. The magnitude of RFH flows is determined mainly by the efficiency of fluid circulation in removing crustal heat, relative to conduction. Lithospheric heat loss drives fluid flow on ridge flanks, leading to differences between pressures at the base of recharging and discharging columns of fluid within the crust. The flowing system effectively functions as a "hydrothermal siphon" (Fisher et al., 2003a; Hutnak et al., 2006; Fisher and Wheat, 2010; Figure 1). Circulating fluids are warmed (relative to bottom water) and expand, such that where discharge occurs, the column

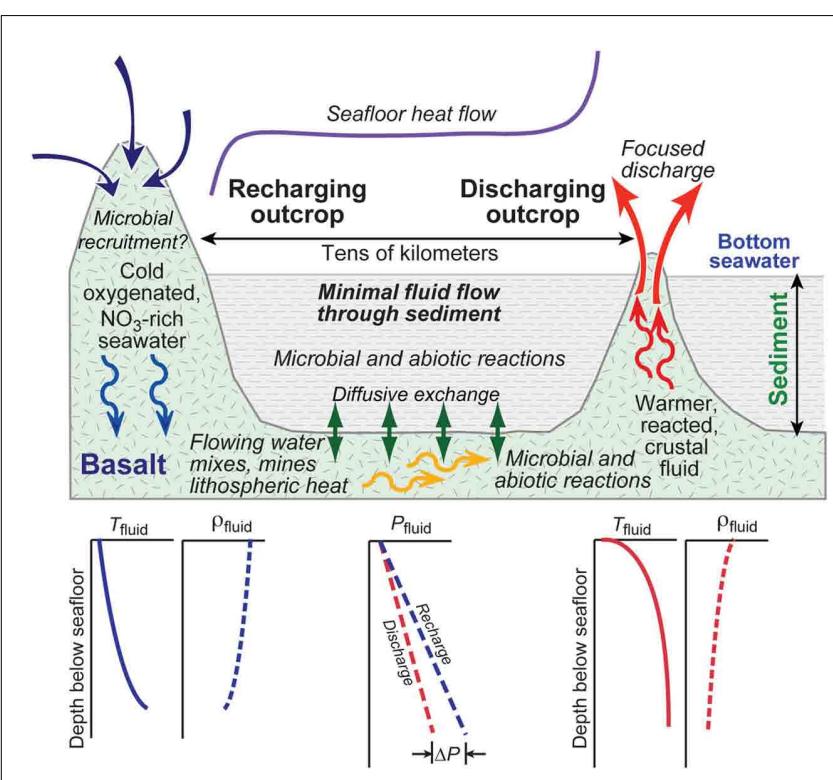

FIGURE 1 | Schematic illustrations of the causes and impacts of ridge flank hydrothermal circulation. In this example, seamounts or other basement outcrops play a key role in guiding fluid flow into and out of the crust, between areas that are blanketed with marine sediment. Within recharging and discharging volcanic rock outcrops, fluid temperatures ( $\left.T_{\text {fluid }}\right)$ and densities ( $\left.r_{\text {fluid }}\right)$ remain relatively constant so long as vertical transport (descent and ascent) is rapid. The difference between fluid pressures ( $\left.P_{\text {fluid }}\right)$ at the base of recharging and discharging columns of fluid (C). $\Delta P$, is the primary driving force for ridge flank hydrothermal circulation. This pressure difference is available to move fluid laterally within the reactive basement aquifer, mining heat, reacting with the crust, and providing nutrients and/or energy to microbial communities living in pore spaces. Seafloor heat flow is generally higher adjacent to discharging outcrops, and lower adjacent to recharging outcrops. Between outcrops, heat flow may be equal to or less than conductive plate cooling values, depending on the regional efficiency of lithospheric heat extraction. 
of fluid rising through the crust has a density that is comparatively low. In contrast, the density of cold bottom seawater entering the crust is comparatively high. So long as there is a good hydrologic connection between recharging and discharging fluids, with the intervening crust having high permeability (ease of flow), fluids will continue to flow because of the density (and associated pressure) contrast. In addition, such systems will flow at a rate that is optimized to remove as much heat from the crust as possible, which often means circulating a large volume of slightly warmed (and slightly altered) fluid rather than a smaller volume of hotter (and more altered) fluid.

\section{MODEL MICROBIAL PROVINCES}

On the basis of the preceding discussion concerning thermal, chemical, hydrological, and geological regimes, we can delineate a modest number of end-member microbial provinces in the volcanic ocean crust (Figure 2) Description of key physical, thermal, and chemical conditions for these biomes is helpful in defining where attention could be placed in the coming decades so as to focus time and resources on locations that can have broad applicability and can influence our understanding of subseafloor microbial processes in general. This approach is different from trying to define a global "average" set of conditions. In a highly heterogeneous environment like the volcanic ocean crust, "average" conditions may actually be rare. Or, like many natural stream systems, it may be end-member conditions (high flow, low flow) that dominate system morphology and the nature of ecosystems.

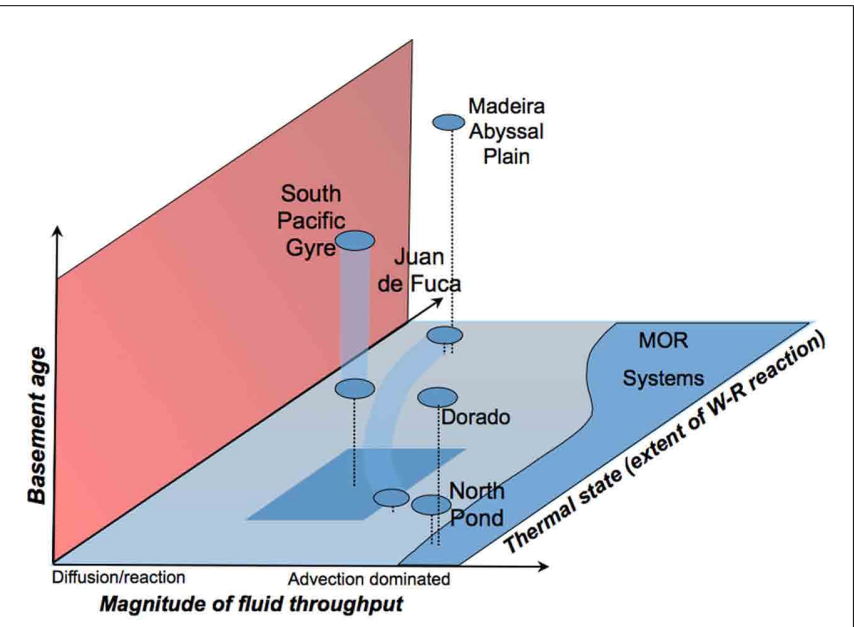

FIGURE 2 | Cartoon illustrating how ridge flank hydrothermal field areas discussed in this paper might vary in terms of three key physical and chemical parameters: age of basement rocks, magnitude of fluid flow through the crust, and then thermal state of the basement aquifer (which indicates the likely extent of water-rock interaction). Information used to construct this figure is listed in Table 1). The height of individual dots indicates basement age, whereas position on the horizontal space indicates fluid and thermal states. The South Pacific Gyre sites span a range of parameters (height of dots indicates range of basement ages, in addition to fluid and thermal state). There are two main parts of the eastern flank of the Juan de Fuca Ridge, indicated by the swath between two dots. Properties of many areas associated with mid-ocean ridges (MORs) are indicative of young basement age, a wide range of temperatures, and additional variability in fluid throughput, as shown.
We propose that three primary factors be considered in selection of characteristic biomes: volcanic crustal age, typical fluid temperature, and the throughput of water (extent of water-rock interaction; Figure 2). Numerous other factors might be selected that are equally illustrative (for example, concentrations of nutrients or dissolved ions, inorganic and organic carbon content in fluids, rock type, spreading rate of crustal formation, or fluid residence time). However, appropriate values for many of these parameters are poorly known on a regional basis, challenging to determine in practice, or may serve as proxies for more direct biological controls in specific field areas.

Plotted in this three-dimensional space are selected locations where subseafloor microbiological work has been completed to date, and where future studies are planned or have been proposed. Characteristics of these sites are summarized in Table 1. We are particularly interested in using this framework to define pairs or sets of sites that share some characteristics, but differ in one or more key aspects, as this will allow the strongest delineation of what factors control the development and maintenance of microbial communities. Once these factors are identified, results from work at a small number of carefully selected field sites can be extrapolated more broadly, both spatially and temporally. The latter is especially important when one considers that subseafloor biomes evolve with time (as the seafloor spreads and ages, lithospheric heat flow declines, and sediment accumulates on top of volcanic rocks), such that researchers working in some settings will be challenged to detangle multiple generations of legacy microbial processes.

\section{EASTERN FLANK OF THE JUAN DE FUCA RIDGE}

There is only one site on Earth where a complete hydrologic flow path through a seafloor hydrothermal system has been delineated with confidence: within 3.5-3.6 million years old crust on the eastern flank of the Juan de Fuca Ridge (JFR; Wheat et al., 2000; Fisher et al., 2003a; Hutnak et al., 2006). In this area, fluids enter Grizzly Bare outcrop, an inactive seamount, traverse more than $50 \mathrm{~km}$ to the northeast, then exit the seafloor through Baby Bare outcrop, with fluid travel time that is likely to be on the order of a few tens of years to a few hundred years. Fluids moving through this

Table 1 | Summary of selected characteristics for sites discussed in this paper.

\begin{tabular}{llll}
\hline Site & $\begin{array}{l}\text { Basement age } \\
\text { (million years) }\end{array}$ & $\begin{array}{l}\text { Fluid } \\
\text { throughput }\end{array}$ & $\begin{array}{l}\text { Thermal state } \\
\text { (W-R reaction) }\end{array}$ \\
\hline Juan de Fuca flank & $0.7-3.6$ & $\begin{array}{l}\text { High to } \\
\text { moderate }\end{array}$ & $\begin{array}{l}\text { Cool (low) to } \\
\text { warm (high) }\end{array}$ \\
North Pond & 8 & High & Cool (low) \\
Dorado outcrop & 23 & High & Cool (low) \\
South Pacific Gyre & $15-100$ & High to low & Cool (low) \\
Madeira Abyssal plain & $\sim 100$ & Low? & Warm (high)
\end{tabular}

Site characteristics are based on studies cited in the next of the paper. Two hydrothermal regimes are discussed for the eastern flank of the Juan de Fuca Ridge, a younger (cooler) area closer to the active spreading center, and an older (warmer) region farther from the spreading center. 
part of the RFH system undergo extensive alteration, and fluid temperatures in the crust reach $\sim 65^{\circ} \mathrm{C}$ before seeping from the seafloor. The only natural seeps that have been sampled from a RFH system were collected on Baby Bare outcrop (Mottl et al., 1998; Wheat and Mottl, 2000). Subsequently a lance was deployed to penetrate thin sediment and create an artificial vent, allowing collection of fluids for microbial characterization (Huber et al., 2006).

To the west of this area, on younger crust, sediment cover is discontinuous, there is greater basement exposure, and RFH systems are generally cooler (Davis et al., 1992; Wheat and Mottl, 1994; Elderfield et al., 1999). This cooler RFH system may be more characteristic of RFH systems on average, with lower temperatures and greater fluid throughput, but because there are more places where fluids could enter and exit the crust in this area, flow paths are poorly constrained.

A transect of eight sites was drilled across 0.9-3.6 Ma seafloor in 1996 (Ocean Drilling Program Leg 168), allowing sample collection and installation of first generation subseafloor borehole observatories (CORKs) within uppermost ocean crust (Davis et al., 1997). No microbial work was planned when these systems were designed or installed, but samples for microbial characterization were collected later from one of the CORKs installed near Baby Bare outcrop (in Hole 1026B), where fluids are warm and reducing (Cowen et al., 2003). IODP Expedition 301 returned to this area in 2004 to drill and sample deeper in basement, replace the Hole 1026B borehole observatory, and establish two new ones, each instrumented with novel downhole microbial colonization experiments (Orcutt et al., 2011a; Smith et al., 2011). A later generation of CORKs was installed during IODP Expedition 327 in 2010, including additional microbial samplers, enrichment experiments, and colonization substrate (Fisher et al., 2011).

CORKs installed in this area during ODP Leg 168 and IODP Expedition 301 have produced valuable fluid and microbial samples indicating the nature of linked geochemical and microbiological conditions in basement (e.g., Cowen et al., 2003; Wheat et al., 2004, 2010; Orcutt et al., 2011a; Smith et al., 2011). Fluids and microbial samples collected at depth in two holes have compositions resulting from reducing conditions in basement. CORKs deployed during IODP Expedition 327 should provide even better samples of endemic microbial communities from the crust, because the newer observatories were designed and constructed with materials so as to be more compatible with microbiological investigations. With respect to the continuum of physical and chemical conditions highlighted earlier, the JFR flank sites span a range of thermal states (cool to warm) and magnitude of fluid flow (diffusion to advection dominated), but all are within relatively young seafloor (Figure 2; Table 1).

\section{NORTH POND}

North Pond is located in the mid-Atlantic at $22^{\circ} \mathrm{N}$ on the western flank of the Mid-Atlantic Ridge. North Pond is an isolated northeast-trending sediment pond bounded by 1-km high basement ridges and a range of sediment thicknesses up to $300 \mathrm{~m}$ thick at the southernmost part of the basin. This was a drilling target during DSDP Leg 45 (Site 395) to examine crustal properties to characterize the geology of young oceanic crust. Here the crust is relatively young ( 8 million years) with vigorous crustal fluid circulation that allows warming of circulating fluids to only $10-15^{\circ} \mathrm{C}$ before they are discharged from the crust. There have been numerous return visits to this area since the initial deep-sea drilling, with the most recent work occurring on IODP Exp 336 to install borehole observatories and experiments and core sediment and volcanic rocks, with a focus on subseafloor microbial systems.

Samples and data collected during a heat flow and sediment coring expedition in 2009 suggest a crustal fluid having considerable dissolved oxygen and seawater-like concentrations for most major and trace ions and nutrients, indicating a short residence time for fluids within basaltic basement. Because temperatures are low, sluggish abiotic rates of reaction favor alteration by kinetically enhanced biotic reactions. These reactions could support microbial communities that alter the crust directly. North Pond was selected for new drilling and CORK installation during IODP Exp 336 in part because of the contrasts it provides with the eastern flank of the JFR (Figure 2; Table 1).

Hydrologically, North Pond is characteristic of areas where volcanic crustal rocks are exposed across large areas, and continuous cover by sediment is the exception rather than the rule (Langseth et al., 1984, 1992). Drilling, coring, logging, and limited borehole experiments suggest that the upper crust in this area is highly porous and permeable (Hickman et al., 1984; Becker, 1990; Gable et al., 1992; Bartetzko et al., 2001). There is extensive, vigorous fluid circulation in the crust of this area, likely more circulation per unit of basement rock than observed where fluids are hotter and more altered on the eastern flank of the JDF, but delineating fluid flow pathways from recharge to discharge around North Pond is challenging. The North Pond microbial province is indicative of low temperature and advection dominated conditions, within relatively young ocean crust (Table $\mathbf{1}$ ).

\section{DORADO OUTCROP}

Dorado outcrop is located on the eastern flank of the East Pacific Rise (EPR) spreading center on the Cocos Plate, off-shore of the Nicoya Peninsula of Costa Rica. Here the crust is about 23 million years old (Barckhausen et al., 2001). Surveys using swath-mapping, multi-channel seismic reflection data, and multi-penetration heat flow measurements identified basement outcrops and delineated thermal anomalies with respect to global lithospheric cooling models and regional heat loss (Fisher et al., 2003b; Hutnak et al., 2007). These surveys revealed that a large part of the Cocos Plate is anomalously cool, having upper basement temperatures of $5-30^{\circ} \mathrm{C}$ below thick sediments, consistent with rapid and extensive shallow fluid circulation through the crust. Comparison of regional seafloor heat flow data to lithospheric model predictions indicates that a seafloor area of $14,500 \mathrm{~km}^{2}$ loses $\sim 1 \mathrm{GW}$ of heat, requiring RFH fluid throughput of $4-80 \mathrm{~m}^{3} / \mathrm{s}$ (Hutnak et al., 2008). This three to four orders of magnitude more fluid than flows from Baby Bare outcrop, and is at the extreme end of what occurs globally on ridge flanks. Most of this fluid enters and exits the crust through a small number of basement outcrops. Dorado outcrop was identified as a location of rapid hydrothermal discharge, and Tengosed Seamount, $20 \mathrm{~km}$ away, is the closest likely conduit for hydrothermal recharge (Fisher et al., 2003b; Hutnak et al., 2008; Wheat and Fisher, 2008). 
Regional basement chemical and thermal conditions around Dorado outcrop are similar to those observed in North Pond, and probably are typical of a large fraction of the global RFH systems. In contrast to North Pond, potential fluid entry and exit points around Dorado outcrop are constrained by regionally thick sediments, which makes delineation of flow paths more feasible. Fluid circulation rates and residence times in the volcanic crust around Dorado outcrop are probably similar to those around North Pond, and at the western end of the JFR flank transect, but the age of basement is three to five times older at the Dorado outcrop (Table 1).

Studies around Dorado outcrop could allow for assessment of how large fluxes of seawater circulation through very permeable pathways alter crust over time. No microbial studies of basement samples have been completed to date near Dorado outcrop, presenting opportunity for low temperature RFH exploration and discovery. A sampling survey is currently planned for 2013, with the primary goal of recovering pristine hydrothermal fluid discharging from Dorado outcrop.

\section{SOUTH PACIFIC GYRE}

The South Pacific Gyre (SPG) is characterized by a region with low surface chlorophyll-a concentrations, a measure of plankton productivity. Low surface productivity results in low sediment organic matter compositions, low sedimentation, and low microbial activity. The region spans much of the Pacific Ocean from $20^{\circ} \mathrm{S}$ to $30^{\circ} \mathrm{S}$ and was sampled on IODP Exp 329 at seven sites having crustal ages of 15-100 million years in locations having 18-131 m of sediment above volcanic crustal rocks. Heat flow from SPG sites younger than 65 million years is generally less than values predicted by conductive lithospheric cooling models, consistent with global datasets, suggesting that a fraction of heat is extracted advectively from the crust (Expedition 329 Scientists, 2011). Heat flow data from older SPG sites are consistent with more sluggish fluid flow and little or no heat extraction by fluids. Throughout the region, temperatures in upper basaltic crust are close to $10^{\circ} \mathrm{C}$.

The SPG region includes features that may be characteristic of several microbial provinces (Figure 2). On younger crust, where fluid flow is most vigorous, RFH systems will be similar to those of North Pond and Dorado outcrop; however, the low microbial activity at SPG sites should limit the sedimentary influence on basalt hosted microbial communities. On older SPC crust, where fluid flow within the crust is limited, thin sediment keeps the temperature in basement relatively low, providing an interesting contrast to both old sites and younger sites where basement temperatures are greater. Sedimentary influences on basaltic basement conditions (e.g., C, Fe, Mn, sulfate) should be minimal in the SPG region. Given the organic matter-starved region of the SPG, metabolic activity may be enhanced by water radiolysis and hydrogen may be the most significant electron donor for microbial respiration.

\section{MADEIRA ABYSSAL PLAIN}

The Madeira Abyssal plain (MAP) comprises a region of $\sim 10^{5} \mathrm{~km}^{2}$ in the Canary Basin, west of the Canary Islands, north Atlantic Ocean (Searle, 1987). The MAP is the deepest part of the Canary Basin, with typical water depth of $5400 \mathrm{~m}$, although the tops of large seamounts to the east (notably parts of the Meteor Seamount chain) extend to within $300 \mathrm{~m}$ of the sea surface. The crustal age in the MAP area is about $106 \mathrm{Ma}$, consistent with slow seafloor spreading at $1.5 \mathrm{~cm} /$ year (Noel, 1985; Searle, 1987). Sediment cover is regionally thick and extensive, both because of the age of the plate and because turbidites have poured into the Canary Basin from continental areas the east, but there are basement outcrops associated with abyssal hill topography, presumably from off axis volcanism.

There are two strong indicators of sustained hydrothermal circulation through old MAP seafloor: thermal and chemical. Variations in heat flow correlate with basement relief and are consistent with fluid circulation at rates of $0.3-3 \mathrm{~m} /$ year, requiring relatively high upper basement permeabilities (Fisher and Von Herzen, 2005). Geochemical data collected during sedimentological studies associated with ODP Leg 157 (Schmincke et al., 1995) show pore water gradients that are reversed at depth, as has been interpreted elsewhere to indicate the passage of relatively young and unreacted fluids through the upper crust (e.g., Baker et al., 1991; Wheat and Mottl, 1994; Elderfield et al., 1999).

No microbiological work has been completed in this area to date, but it is an intriguing site for such investigations for several reasons. This is one of the oldest seafloor locations where hydrothermal circulation is thought to occur (Von Herzen, 2004). Basement outcrops are relatively widely spaced, limiting the number of fluid entry and exit points from the crust. Although sediment in this area is comparatively thick, upper basement temperatures are projected to be only $10-30^{\circ} \mathrm{C}$ because lithospheric heat flow is so low in old crust. This range of temperatures overlaps with those inferred for the western end of the JFR flank area, North Pond, and Dorado outcrop, but MAP fluids pass through crust that is much older. The upper crustal volcanic rocks in the MAP area may have seen $>100$ million years of continued hydrothermal circulation.

The thick accumulations of volcanic and continentally derived sediment in this area are likely to be relatively rich in organic carbon. Diffusive exchange between sediment and upper basement fluids could provide an important source of carbon, or could be insignificant at present because circulation has continued for 100 million years, depleting basal sediment of microbially important substrates. Sample collection from the MAP area offers the intriguing possibility of recovering microbial material that has been physically (and perhaps genetically) isolated for tens of millions of years, but under physical and chemical conditions consistent with younger sites. Rock samples from the MAP area could similarly provide important information on the nature of long-term, integrated rock alteration patterns in association with both inorganic and microbial processes, linking physical, chemical, and microbial controls.

\section{ADDITIONAL CONTROLS ON OCEAN CRUSTAL MICROBIOLOGY}

The five field areas identified above span a range of crustal ages and magnitudes of fluid flow that should comprise and intriguing suite of field sites for comparative microbial studies in RFH systems (Table 1). However, even among these sites, a comparatively narrow array of basement temperatures is represented $\left(\sim 5-65^{\circ} \mathrm{C}\right.$; Figure 2$)$. There are clear gaps in the representation 
of end-member characteristics that we highlight with these sites, particularly those involving rapid fluid flow and high-temperature conditions, or sluggish to no fluid flow and cooler temperatures. The former is likely to be found at MORs (as marked in Figure 2) and in other settings where volcanism occurs (e.g., around volcanically active seamounts). Conditions of sluggish to no fluid flow and cooler temperatures in basement are likely to be rare in nature, occurring perhaps where long-term fluid circulation has clogged fluid pathways through the crust, but the sedimentation rate has remained low, limiting the extent of crustal burial and thermal insulation.

Many additional or alternative physical and chemical parameters could be used to define other characteristics that control RFH microbial environments. For example, some areas have an abundant source of organic carbon in overlying sediment (generally close to continental sources or in areas of sustained upwelling and associated primary productivity, for, e.g., Guaymas basin), whereas others are more carbon limited (e.g., North Pond). A similar approach could be taken with respect to limiting nutrients and microbial energy sources, for example, contrasting upwelling regimes with open ocean sites. There are also likely to be differences associated with sediment type (e.g., carbonate vs. clay content), thickness, and the related spacing of basement outcrops that enhance fluid entry and subsequent discharge from the crust. Other factors that could be considered include spreading rate and mechanisms of crustal construction. For example, there are significant differences in the relative importance of faulting between slow and fast spreading centers, the former being associated with extensive faulting and ridge flank dissection compared to the latter. One could similarly consider the spacing and amplitude of abyssal hill topography, or other aspects of crustal tectonic fabric. The selection of defining characteristics for end-member microbial provinces is, by necessity, somewhat arbitrary. That said, it makes sense to select parameters that can be mapped and delineated relatively easily using conventional (regional) survey techniques, so that a modest number of field sites can be selected for more intensive (expensive, difficult, time consuming) study. Whatever parameters are chosen for comparative purposes, the approach outlined in this study can be beneficial for understanding why crustal microbial systems occur as they do, and what strategies have been developed within these systems for survival across long periods of geological time.

\section{TECHNOLOGY}

The preceding discussion of RFH provinces suggests that there are a number of targets available for microbial studies. Yet locating positions of seawater input to, and fluid egress from, RFH systems remains challenging. At MORs, focused venting of hydrothermal fluids generates chemical, thermal, and microbial plumes that can be traced from the water column back to seafloor vents many kilometers away. In contrast, on ridge flanks such plumes may rise only meters to tens of meters, and will be difficult to distinguish from bottom water even under ideal survey conditions. Most RFH sites have been discovered using combined geophysical and geochemical methods (seismic data, heat flow measurements, and pore water composition from sediment gravity cores). Submersible or
ROV operations are then required to identify and sample sites of focused fluid flow.

The research community needs to sample multiple sites that are representative of overlapping biomes, to quantify the physical, chemical, and hydrologic conditions that control microbial development. Given the vastness of the seafloor, and the need to nest detailed studies within coarser surveys, technical advances in survey tools are required. For example, long-range, autonomous gliders with seismic sensors (chirp sonar) are needed to survey large expanses near basaltic outcrops. Such surveys coupled with systematic heat flow surveys are required to assess the vigor of local and regional fluid circulation in the crust. Autonomous vehicles are also needed that can acquire highquality bathymetric maps and sample the water column to identify RFH plumes. The latter will require considerable improvement to sensor capabilities to allow detection of subtle chemical and microbial plume characteristics that are the most promising for remote plume detection. Although some, but certainly not all, of these sampling capabilities are present in existing AUVs; however, power consumption limits dive time to $\sim 12 \mathrm{~h}$. Thus, to survey even a small portion of the ridge flanks would require a fleet of AUVs each conducting a portion of the overall mission (Figure 3).

Once sites of fluid seepage from basaltic crust are located, sampling for and in situ measurements of microbiological characterization can commence. There are additional technological

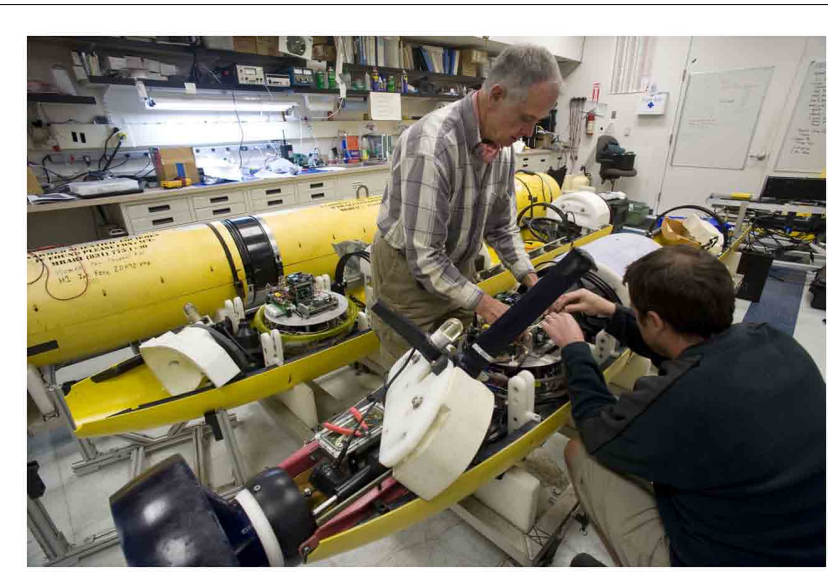

FIGURE 3 | Duane Thompson and Doug Conlin prepare a benthic imaging AUV. The two other AUVs are an upper water column vehicle and a mapping vehicle. Although the nose and tail cones are identical, the payload of each AUV is specifically designed for a particular mission. No AUV in existence has the combined components to tackle the initial mission of searching for RFH venting and detecting chemical and microbial characteristics of the venting fluid. Such a vehicle would require significant power for its sonars and must be able to rechargeable its batteries to explore the vastness of the ridge flanks where hundreds of thousands of small outcrops exist. Small outcrops tend to be sites where fluids seep from the crust and are not detected by satellite gravimetry measurements. Long-range vehicles (e.g., gliders) exist but are underpowered for such a mission. Vehicles and sonars with appropriate capabilities exist but are limited to an 12-h dive and lack the suite of sensors required for detecting chemical and microbial signatures of RFH venting. Copyright MBARI 2010 Photo by Todd Walsh. 
challenges pertaining to sample contamination and preservation. In situ systems capable of pumping fluids into multiple sterile bags and filters have been established (Butterfield et al., 2004; Cowen et al., 2012), but remain developmental and require significant technical expertise to operate. Simpler syringe-style samplers have been deployed for single 50-100 ml discrete samples that can be used in concert with a filter or in situ preservation (Fisher et al., 2012). Presently, the only deep-sea in situ microbial measurements are those from the environmental processing system (ESP; Scholin et al., 2009) and deep ultra-violet fluorescent technologies such as the Deep Exploration Biosphere Investigative tool (DEBI-t; based on technology adapted from Bhartia et al., 2010), both presently impractical for wide-spread use.

Because of the limited number of known sites of focused fluid seepage from RFH systems, studies of microbial community and processes have looked toward analyzing materials from deep-ocean drilling. At present, molecular techniques are challenging to apply directly to recovered igneous materials, because of poor and biased recovery (10-30\% overall in upper volcanic crust, generally favoring more massive rocks), contamination during drilling, and low cell counts and analytical interference with the crustal matrix. A few studies have been successful to date working with recovered volcanic materials (Mason et al., 2010; Santelli et al., 2010). Analytical advances in this area will greatly increase productivity on future deep-ocean drilling operations.

Because of these sampling recovery and analytical issues, an alternative approach to studying microbial processes in the ocean crust are through the development and use of borehole observatories (CORKs; Davis et al., 1997). On the basis of initial microbial studies harbored in situ within a borehole (Orcutt et al., 2011a; Smith et al., 2011), CORK observatories have been modified and deployed to enhance the return of microbial data while minimizing artifacts. For example, on IODP Exp 336 three new CORKs were deployed, some with multiple sampling horizons and each using materials that minimize additional carbon sources and potential REDOX reactions (coated steel, fiberglass, and high density plastic; Edwards et al., 2010). To examine reaction pathways in situ, transects of drill holes and CORK observatories are required in order to intersect hydrological units of interest within the volcanic crust.

Improvements and versatility are incorporated in each new CORK system. The first generation of CORK observatories were often successful on initial deployment, but were not designed to facilitate collection of high-quality borehole fluid and microbial samples nor house in situ experiments. Some of these CORK systems remain operational more than two decades after deployment, although others have failed over time. Later generations of CORKs, including those that isolate multiple depth intervals, contain redundant seal systems, and were designed for installation deep within unstable boreholes, are generally more difficult to deploy. Approximately half to two thirds of modern CORKs are successfully installed as intended. Technical challenges can be addressed, but this requires extensive planning, long lead times, attention, and considerable financial resources. Ultimately the number of CORK observatories that will be deployed in the next 10-20 years for microbial studies is going to be limited, perhaps 10-20 in total. This makes it essential to select sites in the context of the microbial province concept, so that results from each system can be used to leverage other studies.

Additional technical advances are needed for in situ samplers, sensors, and experiments. Presently systems for deployment within boreholes well below the seafloor have been limited to designs that use osmotic-powered pumps (Wheat et al., 2011). While such designs offer a variety of sampling and experimental possibilities, the borehole environment does not prelude electrically powered sensors. Several such sensors have been deployed for geophysical study (e.g., Kopf et al., 2011) and only a downhole dissolved oxygen sensor exists for microbial characterization. In contrast, seafloor samplers and sensors can tap into hydrologic horizons of interest through the use of an umbilical - stainless steel or hardened Teflon coated tubing with a valve at the wellhead and open to the formation at depth. The present technology includes a pump system that pulls fluid up the umbilical to the seafloor and pushes borehole fluids past a variety of sensors and into samplers (Cowen et al., 2012). Here, bringing the laboratory to the seafloor and conducting manipulative (e.g., rate and enrichment) experiments are critical next steps to further our understanding of RFH microbial environments. For example, near term technological advances for wellhead sampling and sensing operations include mass spectrometry and fast flow osmotic pumps for continuous sampling of borehole fluids via the umbilical. Other technological advances could include a flow cytometer or other visual-based (light or laser) systems for microbial detection or characterization (e.g., DEBI-t). As in the past, present studies in borehole observatories will evolve future instrumentation needs.

Unfortunately, opportunities to deploy CORK observatories are likely to remain limited because of ongoing fiscal, scheduling, and technical challenges. Hardware and downhole science materials for a single borehole observatory can cost as much as \$1 million US, depending on complexity. Plans often need to be developed over a period of several years given long lead times for delivery of key components, and the need to facilitate multiple experimental and observational goals (geophysical, hydrologic, biogeochemical, microbial). Even with rigorous planning, deployment is frequently difficult. Following deployment, there remain ongoing technological, logistical, and fiscal challenges for maintaining CORKs, monitoring borehole conditions, and conducting experiments. Ship time and submersibles or ROVs are required for nearly all observatory work (the exception is a CORK that is tied to a cabled network, e.g., Neptune). Given the nature of microbiological analysis, which requires physical samples, all microbiological observatory work requires that researchers physically access the borehole.

There are 30 "legacy" boreholes from past deep-ocean scientific drilling expeditions that have been drilled into basement and cased through the sediment. Presumably these boreholes are open to basaltic crust and could be sampled with wire-line sensing and sampling systems that need to be developed or through a modified borehole observatory design (CORK). At the writing of this manuscript, IODP Hole U1383B is one such candidate borehole. It has a reentry cone and is cased through the sediment section with open borehole into basalt below the casing. In the spring of 2012, researchers will deploy a long-term observatory in this borehole. The ROV Jason II will deploy the new wellhead and downhole sampler-sensor-experiment string to monitor 
the chemical composition of ocean crustal fluids and microbial communities and to conduct microbial enrichment experiments. Similar deployments are possible at other legacy boreholes, which would help to expend sampling and monitoring across a wider range of physical and chemical conditions.

\section{CONCLUSION}

We have described the overall nature of RFH systems, and discussed a means for characterizing these systems based on determination of fundamental physical and chemical characteristics. We illustrated this approach through presentation of example RFH systems that occupy specific regions on a plot of RFH parameter space (Figure 2; Table 1), helping to define a range of microbial provinces found below the ocean on a global basis. We also discussed some of the technological hurdles associated with studying these systems that must be overcome in the next few decades.

The framework we propose for understanding geological, geochemical, and hydrological links to ocean crustal microbial systems can be used to guide future site selection. We acknowledge that numerous additional factors may be important in determining the nature of crustal microbial ecosystems, including the availability of nutrients, carbon, and energy sources. While these and other factors certainly are important, they generally do not lend themselves well to evaluation based on regional surveys, and so

\section{REFERENCES}

Baker, E. T. (2007). Hydrothermal cooling of midocean ridge axes: do measured and modeled heat fluxes agree. Earth Planet. Sci. Lett. 263, 140-150.

Baker, P., Stout, P., Kastner, M., and Elderfield, H. (1991). Large-scale lateral advection of seawater through oceanic crust in the central equatorial Pacific. Earth Planet. Sci. Lett. 105, 522-533.

Barckhausen, U., Renaro, C., von Huene, R., Cande, S. C., and Roeser, H. A. (2001). Revised tectonic boundaries in the Cocos Plate off Costa Rica: implications for the segmentation of the convergent margin and for plate tectonic models. J. Geophys. Res. 106, 19,207-19,220.

Bartetzko, A., Pezard, P., Goldberg, D., Sun, Y.-F., and Becker, K. (2001). Volcanic stratigraphy of DSDP/ODP Hole 395A: an interpretation using well-logging data. Mar. Geophys. Res. 22, 111-127.

Becker, K. (1990). "Measurements of the permeability of the upper oceanic crust at Hole 395A, ODP Leg 109," in Proceedings of Ocean Drilling Program, Scientific Results, eds R. Detrick, J. Honnorez, W. B. Bryan, and T. Juteau (College Station, TX: Ocean Drilling Program), 213-222.

Bhartia, R., Salas, E. C., Hug, W. F., Reid, R. D., Lane, D. J., Edwards, K. J., and Nealson, K. H. (2010). Label-free bacterial imaging with deep UV laser induced native fluorescence. Appl. Environ. Microbiol. 76, 7231-7237.
Butterfield, D. A., Roe, K. K., Lilley, M. D., Huber, J., Baross, J. A., Embley, R. W., and Massoth, G. J. (2004). "Mixing reaction and microbial activity in sub-seafloor revealed by temporal and spatial variation in diffuse flow vents at axial volcano," in The Subseafloor Biosphere at Mid-Ocean Ridges, eds R. W. Wilcock, E. F. DeLong, D. P. Kelley, J. A. Baross, and C. Cary (Washington, DC: American Geophysical Union), 269-289.

Cann, J. R. (1974). A layered model for oceanic crust developed. Geophys. J. R. Astron. Soc. 39, 169-187.

Chyba, C. F., and Phillips, C. B. (2002). Europa as an abode for life. Orig. Life Evol. Biosph. 32, 47-67.

Cody, G. D., Boctor, N. Z., Filley, T. R., Hazen, R. M., Scott, J. H., Sharma, A., and Yoder, H. S. Jr. (2000). Primordial carbonylated iron-sulfur compounds and the synthesis of pyruvate. Science 289, 1377-1340.

Coogan, L. A., Jenkins, G. R., and Wison, R. N. (2007). Contrasting cooling rates in the lower oceanic crust at fast- and slow-spreading ridges revealed by geospeedometry. J. Petrol. 48, 3311-2231.

Cowen, J. P., Copson, D. A., Jolly, J., Hsieh, C.-C., Lin, H.-T., Glazer, B. T., and Wheat, C. G. (2012). Advanced instrument system for real-time and sampling of the deep (basaltic) crustal biosphere. Deep Sea Res. Part I Oceanogr. Res. Pap. 61, 43-56. time-series microbial geochemical

have limited applicability in terms of identifying key locations for future studies. This may change with advances in technology and improved availability of established tools, and additional sites will be identified serendipitously during surveys planned for other purposes.

This is truly an "age of exploration" for microbiological study of RFH systems, and many more aspects of them and new sites will surely be identified in the future, hopefully guided by strategies that maximize return on knowledge that can be applied on a global basis, rather than understanding of individual sites in isolation. Big picture projects require large teams of researchers from multiple disciplines to come together to properly plan and coordinate complex programs, and this requires taking a long-term view. But worked completed and discoveries made to date show that patience, persistence, and vision can pay off over time.

\section{ACKNOWLEDGMENTS}

This research was supported by the US National Science Foundation grants OCE 0939564 (to Katrina J. Edwards with subawards to Andrew T. Fisher, C. Geoffrey Wheat), OCE-0727952 (Andrew T. Fisher), OCE-1031808 (Andrew T. Fisher), OCE-1130146 (C. Geoffrey Wheat), and 1030061 (C. Geoffrey Wheat), by US Science Support Program for IODP projects T327A7 and T327B7 (Andrew T. Fisher). This is C-DEBI contribution \#1XX.

Cowen, J. P., Giovannoni, S. J., Kenig, F., Johnson, H. P., Butterfield, D., Rappé, M. S., Hutnak, M., and Lam, P. (2003). Fluids from ageing ocean crust that support microbial life. Science 299, 120-123.

Davis, E. E., Chapman, D. S., Mottl M. J., Bentkowski, W. J., Dadey, K., Forster, C., Harris, R., Nagihara, S., Rohr, K., Wheat, G., and Whiticar, M. (1992). FlankFlux: an experiment to study the nature of hydrothermal circulation in young oceanic crust. Can. J. Earth Sci. 29, 925-952.

Davis, E. E., Fisher, A. T., and Firth, J. (1997). Proceedings of Ocean Drilling Program Initial Reports, Vol. 168 (College Station, TX: Ocean Drilling Program), 470.

Dunn, R. A., Toomey, D. R., and Solomon, S. C. (2000). Threedimentional seismic structure and physical properties of the crust and shallow mantle beneath the East Pacific Rise at $9^{\circ} 30^{\prime}$ N. J. Geophys. Res. 105, 23537-23555.

Edwards, K. J., Bach, W., and Klaus, A. (2010). Integrated Ocean Drilling Program Prospectus, Expedition 336. College Station: IODP.

Elderfield, H., and Schultz, A. (1996). Mid-ocean ridge hydrothermal fluxes and the chemical composition of the ocean. Annu. Rev. Earth Planet. Sci. 24, 191-224.

Elderfield, H., Wheat, C. G., Mottl, M. J., Monnin, C., and Spiro, B. (1999). Fluid and geochemical transport through oceanic crust: a transect across the eastern flank of the Juan de Fuca Ridge. Earth Planet. Sci. Lett. 172, 151-165.

Expedition 327 Scientists. (2010). The Hydrogeologic Architecture of Basaltic Oceanic Crust: Compartmentalization, Anisotropy, Microbiology, and Crustal-Scale Properties on the Eastern Flank of Juan de Fuca Ridge, Eastern Pacific Ocean. Integrated Ocean Drilling Program Expedition 327 Preliminary Report, College Station. doi:10.2204/iodp.pr.327.2010

Expedition 329 Scientists. (2011). South Pacific Gyre Subseafloor Life. Integrated Ocean Drilling Program Expedition 329 Preliminary Report, College Station. doi:10.2204/iodp.pr.329.2011

Fisher, A. T. (2003). "Geophysical constraints on hydrothermal circulation: observations and models," in Energy and Mass Transfer in Submarine Hydrothermal Systems, eds $\mathrm{P}$. Halbach, V. Tunnicliffe, and J. Hein (Berlin: Dahlem University Press), 29-52.

Fisher, A. T., Davis, E. E., Hutnak, M., Spiess, V., Zühlsdorff, L., Cherkaoui, A., Christiansen, L., Edwards, K., Macdonald, R., Villinger, H., Mottl, M. J., Wheat, C. G., and Becker, K. (2003a). Hydrothermal recharge and discharge across 50 $\mathrm{km}$ guided by seamounts on a young ridge flank. Nature 421, 618-621. 
Fisher, A. T., Stein, C. A., Harris, R. N., Wang, K., Silver, E. A., Pfender, M., Hutnak, M., Cherkaoui, A., Bodzin, R., and Villinger, H. (2003b). Abrupt thermal transition reveals hydrothermal boundary and role of seamounts within the Cocos Plate. Geophys. Res. Lett. 30, 1550.

Fisher, A. T., Tsuki, T., Petronotis, K., Wheat, C. G., Becker, K., Clark, J. F., Cowen, J., Edwards, K. J., and the IODP Expedition 327 and Atlantis Expedition AT18-07 Shipboard Parties. (2012). Installing and servicing borehole crustal observatories to run three-dimensional cross-hole perturbation and monitoring experiments on the eastern flank of the Juan de Fuca Ridge: IODP Expedition 327 and Atlantis Expedition AT18-07. Sci. Drill. 13 (in press).

Fisher, A. T., Wheat, C. G., Becker, K., Cowen, J., Orcutt, B., Hulme, S., Inderbitzen, K., Haddad, A., Pettigrew, T. L., Davis, E. E., Jannasch, H., Grigar, K., Aduddell, R., Meldrum, R., Macdonald, R., and Edwards, K. J. (2011). "Design, deployment, and status of borehole observatory systems used for single-hole and cross-hole experiments, IODP Expedition 327, eastern flank of the Juan de Fuca Ridge," in Proceedings of Integrated Ocean Drilling Program 327, eds A. T. Fisher, T. Tsuji, and K. Petronotis (Tokyo: IODP). doi:10.2204/iodp.proc.327.107.2011

Fisher, A. T., and Von Herzen, R. (2005). Models of hydrothermal circulation within $106 \mathrm{Ma}$ seafloor: constraints on the vigor of fluid circualtion and crustal properties below the Madeira Abyssal Plain. Geochem. Geophys. Geosyst. 6. doi:10.1029/2005GC001013

Fisher, A. T., and Wheat, C. G. (2010). Seamounts as conduits for massive fluid, heat, and solute fluxes on ridge flanks. Oceanography 23 , 74-87.

Gable, R., Morin, R. H., and Becker, K. (1992). Geothermal state of DSDP Holes 333A, 395A and 534A: results from the dianaut program. Geophys. Res. Lett. 19, 505-508.

Haymond, R. M., Fornari, D. J., Von Damm, K. L., Lilley, M. D., Perfit, M. R., Edmond, J. M., Shanks, W. C., Lutz, R. A., Grebmeier, J. M., Carbotte, S., Wright, D., McLaughlin, E., Smith, M., Beedle, N., and Olson, E. (1993). Volcanic eruption of the mid-ocean ridge along the East Pacific Rise crest at $9^{\circ} 45$ $52^{\prime} \mathrm{N}$ : direct submersible observations of seafloor phenomena associated with an eruption event in April
1991. Earth Planet. Sci. Lett. 119, 85-101.

Hickman, S. H., Langseth, M. G., and Svitek, J. F. (1984). "Initial reports," in Deep Sea Drilling Project, Vol. 78B, eds R. D. Hyndman and M. H. Salisbury (Washington, DC: U. S. Govt. Printing Office), 699-708.

Hillier, J. K., and Watts, A. B. (2007). Global distribution of seamounts from ship-track bathymetry data. Geophys. Res. Lett. 34. doi:10.1029/2007GL029874

Huber, J. A., Johnson, H. P., Butterfield, D. A., and Baross, J. A. (2006) Microbial life in ridge flank crustal fluids. Environ. Microbiol. 8, 88-99.

Humphris, S. E., and Cann, J. R. (2000). Constraints on the energy and chemical balances of the modern TAG and ancient Cyprus seafloor sulfide deposits. J. Geophys. Res. 105, 428477-428488.

Hutnak, M., Fisher, A. T., Harris, R., Stein, C., Wang, K., Spinelli, G., Schindler, M., Villinger, H., and Silver, E. (2008). Large heat and fluid fluxes driven through mid-plate outcrops on ocean crust. Nat. Geosci. 1, 611-614.

Hutnak, M., Fisher, A. T., Stein, C. A., Harris, R., Wang, K., Silver, E., Spinelli, G., Pfender, M., Villinger, H., Pisani, P. C., Deshon, H., and MacKnight, B. (2007). "The thermal state of 18-24 Ma upper lithosphere subducting below the Nicoya Peninsula, northern Costa Rica margin," in MARGINS Theoretical Institute: SIEZE Volume, eds T. Dixon, C. Moore, E. Silver, S. Stein, K. Furlong, and K. Brown (New York: Columbia University Press), 86-122.

Hutnak, M., Fisher, A. T., Zühlsdorff, L., Spiess, V., Stauffer, P., and Gable, C. W. (2006). Hydrothermal recharge and discharge guided by basement outcrops on 0.7-3.6 Ma seafloor east of the Juan de Fuca Ridge: observations and numerical models. Geochem. Geophys. Geosyst. 7. doi:10.1029/2006GC001242

IODP. (2003). Earth, Oceans, and Life. IODP

IODP. (2011). Discovering Earth's Hidden Frontiers Through Scientific Ocean Drilling. MD: IODP.

Johnson, H. P., and Pruis, M. J. (2003). Fluxes of fluid and heat from the oceanic crustal reservoir. Earth Planet. Sci. Lett. 216, 565-574.

Kadko, D., and Moore, W. (1988). Radiochemical constraints on the crustal residence time of submarine hydrothermal fluids: endeavour ridge. Geochim. Cosmochim. Acta 52, 659-668.
Kopf, A., Saffer, D. M., Davis, E., Hammerschmidt, S., LaBonte, A. Meldrum, R., Toczko, S., Lauer R., Heesemann, M., Macdonald, R., Wheat, C. G., Jannasch, H. W. Edwards, K., Orcutt, B., Haddad, A., Villinger, H., Araki, E., Kitada, K., Kimura, T., and Kido, Y. (2011) "The SmartPlug and GeniusPlug: simple retrievable observatory systems for NanTroSEIZE borehole monitoring," in Proceedings of the Integrated Ocean Drilling Program, Vol. 322, eds A. Kopf, E. Araki, S. Toczko (College Station: IODP). doi:10.2204/iodp.proc.332.105.2011

Langseth, M. G., Becker, K., Von Herzen, R. P., and Schultheiss, P. (1992). Heat and fluid flux through sediment on the western flank of the Mid-Atlantic Ridge: a hydrogeological study of North Pond. Geophys. Res. Lett. 19, 517-520.

Langseth, M. G., Hyndman, K., Becker, R. D., Hickman, S. H., and Salisbury, M. H. (1984). "The hydrogeological regime of isolated sediment ponds in mid-oceanic ridges," in Initial Reports Deep Sea Drilling Projects, eds R. H. Hyndman and M. H. Salisbury (Washington, DC: U.S. Government Printing Office), 825-837.

Mackenzie, F. T. (1992). Chemical Mass Balance Between Rivers and Oceans. Encyclopedia of Earth System Science. New York: Academic Press.

Mason, O. U., Di Meo-Savoie, C., Van Nostrand, J. D., Zhou, J., Fisk, M. R. and Giovannoni, S. J. (2010). First investigation of the microbiology of the deepest layer of ocean crust. PLoS ONE 5, e15399. doi:10.1371/journal.pone.0015399

Moores, E. M., and Vine, F. J. (1971). The Troodos massif, Cyprus, and other ophiolites as oceanic crust: evaluations and implications. Proc. R. Soc. Lond. A Math. Phys. Sci. 268 , 443-466.

Mottl, M. J., and Wheat, C. G. (1994). Hydrothermal circulation through mid-ocean ridge flanks: fluxes of heat and magnesium. Geochim. Cosmochim. Acta 58, 2225-2237.

Mottl, M. J., Wheat, C. G., Baker, N., Davis, E. E., Feely, R. A., Grehan, A., Kadko, D., Lilley, M., Massoth, G. Moyer, C., and Sansone, F. (1998). Warm springs discovered on $3.5 \mathrm{Ma}$ oceanic crust, eastern flank of the Juan de Fuca Ridge. Geology 26, 51-54.

Noel, M. (1985). Heat flow, sediment faulting and porewater advection in the Madeira Abyssal Plain. Earth planet. Sci. Lett. 73, 398-406.
Orcutt, B. N., Bach, W., Becker, K., Fisher, A. T., Hentscher, M., Toner, B. M., Wheat, C. G., and Edwards, K. J. (2011a). Colonization of subsurface microbial observatories deployed in young ocean crust. ISME J. 5, 692-703.

Orcutt, B. N., Sylvan, J. B., Knab, N. J., and Edwards, K. J. (2011b). Microbial ecology of the dark ocean above, at and below the seafloor. Microbiol. Mol. Biol. Rev. 75, 361-422.

Parsons, B., and Sclater, J. G. (1977). An analysis of the variation of ocean floor bathymetry and heat flow with age. J. Geophys. Res. 82, 803-829.

Raitt, R. W. (1963). "The crustal rocks," in The Sea, Vol. 3, The Earth Beneath the Sea, ed. M. N. Hill (New York: Wiley-Interscience), 85-102.

Santelli, C. M., Bach, W., Banerjee, N. R., and Edwards, K. J. (2010). Tapping the subsurface ocean crust biosphere: low biomass and drillingrelated contamination calls for improved quality controls. Geomicrobiol. J. 27, 158-169.

Schmincke, H.-U., Weaver, P. P. E., Firth, J. V., and Shipboard Scientific Party. (1995). Leg 157, Vol. 157. College Station, TX: Ocean Drilling Program, 841.

Scholin, C. G., Doucette, S., Jensen, S., Roman, B., Pargett, D., Marin, R. I., Preston, C., Jones, W., Feldman, J., Everlove, C., Harris, A., Alvarado, N., Massion, E., Birch, J., Greenfield, D., Vrijenhoek, R., Mikulski, C., and Jones, K. (2009). Remote detection of marine microbes, small invertebrates, harmful algae and biotoxins using the environmental sample processor (ESP). Oceanography 22, 158-167.

Schrenk, M. O., Huber, J. A., and Edwards, K. J. (2009). Microbial provinces in the subseafloor. Oceanography 2, 85-110.

Searle, R. C. (1987). "Regional setting and geophysical characterization of the Great Meteor East area in the Maderia Abyssal Plain," in Geology and Geochemistry of Abyssal Plains, eds P. P. E. Weaver and J. Thomson (London: The Geological Society of London), 49-70.

Shor, G. G. Jr., Menard, W. H., and Raitt, R. W. (1971). "Structure of the Pacific basin," in The Sea, Vol. 4, New Concepts of Sea Floor Evolution, ed A. E. Maxwell (New York: Wiley-Interscience), 3-27.

Shrenk, M. O., Huber, J. A., and Edwards, K. J. (2009). Microbial provinces in the subseafloor. Oceanography 2, 279-304.

Smith, A., Popa, R., Fisk, M., Nielsen, M., Wheat, C. G., Jannasch, H., 
Fisher, A. T., Becker, K., Sievert, S. M., and Flores, G. (2011). In situ enrichment of ocean crust microbes on igneous minerals and glasses using an osmotic flowthrough device. Geochem. Geophys. Geosyst. 12, Q06007.

Spinelli, G. A., and Harris, R. N. (2011). Effects of the legacy of axial cooling on partioning of hydrothermal heat extraction from oceanic lithosphere. J. Geophys. Res. 116. doi:10.1029/2011JB008248

Stein, C. A., and Stein, S. (1994). Constraints on hydrothermal heat flux through the oceanic lithosphere from global heat flow. J. Geophys. Res. 99, 3081-3095.

VanTongeren, J. A., Kelemen, P. B., and Hanghoi, K. (2008). Cooling rates in the lower crust of the Oman ophiolite: Ca in olivine, revisited. Earth Planet. Sci. Lett. 267, 69-82.

Von Herzen, R. P. (2004). “Geothermal evidence for continuing hydrothermal circulation in older (>60 Ma) ocean crust," in Hydrogeology of the Oceanic Lithosphere, eds. E. E. Davis, and H. Elderfield (Cambridge: Cambridge University Press), 414-450.
Wessel, P., Sandwell, D. T., and Kim, S.-S. (2010). The global seamount census. Oceanography 23, 24-33.

Wheat, C. G., Elderfield, H., Mottl, M. J., and Monnin, C. (2000). Chemical composition of basement fluids within an oceanic ridge flank: implications for alongstrike and across-strike hydrothermal circulation. J. Geophys. Res. 105, 13437-13447.

Wheat, C. G., and Fisher, A. T. (2008). Massive, low-temperature hydrothermal flow from a basaltic outcrop on $23 \mathrm{Ma}$ seafloor of the Cocos Plate: chemical constraints and implications. Geochem. Geophys. Geosyst. 9, Q12O14. doi:10.1029/2008GC002136

Wheat, C. G., Jannasch, H., Fisher, A. T., Becker, K., Sharkey, J., and Hulme, S. (2010). Subseafloor seawaterbasalt-microbe reactions: continuous sampling of borehole fluids in a ridge flank environment. Geochem. Geophys. Geosyst. 11, Q07011. doi: 10.1029/2010GC003057.

Wheat, C. G., Jannasch, H. W., Kastner, M., Hulme, S., Cowen, J., Edwards, K., Orcutt, B. N., and Glazer, B. (2011). "Fluid sampling from oceanic borehole observatories: design and methods for CORK activities (1990-2010)," in Proceedings of the IODP, Expedition 327, eds A. T. Fisher, T. Tsuji, and K. Petronotis (Tokyo: Integrated Ocean Drilling Program Management International, Inc.), doi: 10.2204/iodp.proc.327.109.2011

Wheat, C. G., Jannasch, H. W., Kastner, M., Plant, J. N., DeCarlo, E., and Lebon, G. T. (2004). Venting formation fluids from deep-sea boreholes in a ridge flank setting: ODP Sites 1025 and 1026. Geochem. Geophys. Geosyst. 5, Q08007.

Wheat, C. G., McManus, J., Mottl, M. J., and Giambalvo, E. (2003). Oceanic phosphorous imbalence: the magnitude of the ridge-flank hydrothermal sink. Geophys. Res. Lett. 30, OCE5.1OCE5.4.

Wheat, C. G., and Mottl, M. J. (1994). Hydrothermal circulation, Juan de Fuca Ridge eastern flank: factors controlling basement water composition. J. Geophys. Res. 99, 3067-3080.

Wheat, C. G., and Mottl, M. J. (2000). Composition of pore and spring waters from baby bare: global implications of geochemical fluxes from a ridge flank hydrothermal system. Geochim. Cosmochim. Acta 64, 629-642.

Conflict of Interest Statement: The authors declare that the research was conducted in the absence of any commercial or financial relationships that could be construed as a potential conflict of interest.

Received: 04 November 2011; paper pending published: 23 November 2011; accepted: 05 January 2012; published online: 03 February 2012.

Citation: Edwards KJ, Fisher AT and Wheat CG (2012) The deep subsurface biosphere in igneous ocean crust: frontier habitats for microbiological exploration. Front. Microbio. 3:8. doi: 10.3389/fmicb.2012.00008

This article was submitted to Frontiers in Extreme Microbiology, a specialty of Frontiers in Microbiology.

Copyright (C) 2012 Edwards, Fisher and Wheat. This is an open-access article distributed under the terms of the Creative Commons Attribution Non Commercial License, which permits non-commercial use, distribution, and reproduction in other forums, provided the original authors and source are credited. 